\title{
CULPA Y CASTIGO EN LA ANTIGUA GRECIA
}

\author{
Claudio Palavecino Cáceres* \\ Universidad de Chile
}

\begin{abstract}
RESUMEN: El autor discute el tópico de que los griegos de la época arcaica y clásica desconocieran la culpa personal como fundamento del castigo penal o divino y que esta sea una conquista de la antigüedad tardía. Afirma que en los grandes trágicos e incluso en los monumentos más antiguos de la literatura griega, un análisis más sutil de aparentes casos de castigo sin culpa revela faltas personales de quienes sufren la ira de los dioses o de la polis.
\end{abstract}

Palabras clave: griegos-dioses-culpa-castigo divino-pena.

ABSTRACT: The author discuses the topic about the unknowing of the ancient and clasic greeks of the the personal guilt as a fundament of the criminal or divine punishment, being this a conquest of the late antiquity. He affirms that in the great tragics and even in the most ancient monuments of the greek literature a more subtle analysis of aparent cases of punishment without guilt reveals personal faults of those qho suffer the wrath of the gods or the polis.

Key words: greeks-gods-guilt-punishment divine-punishment.

¿No han de sufrir cosas terribles los que acometieron actos terribles?

Eurípides, Orestes, 413.

En el Orestes de EURÍPIDES, el héroe que da nombre a la tragedia se queja ante Menelao del insoportable acoso de las Erineas, innombrables "doncellas semejantes a la noche", que le provocan ataques de locura, como castigo por el asesinato de su madre, Clitemnestra. Su interlocutor le pregunta si no han de sufrir cosas terribles los que acometieron actos terribles. El héroe le explica que fue el mismísimo Febo Apolo quien le ordenó ejecutar el matricidio. Menelao replica si acaso el dios "era a tal punto ignorante del bien y la justicia". Frente a lo cual Orestes sentencia: "somos esclavos de los dioses, sean lo que sean los dioses".

Esta afirmación resulta difícil de digerir para la mentalidad moderna. Para nosotros, la reprochabilidad de un acto descansa precisamente en la posibilidad que tuvo el autor de comportarse de otro modo, la cual presupone, evidentemente, la evitabilidad individual del hecho y, con ello, el libre albedrío ${ }^{1}$. Esta fundamentación del castigo sería, se dice, una conquista de la Antigüedad tardía. Se suele afirmar, en efecto, que la necesidad de una culpa personal como fundamento del castigo penal o divino aparece, recién, con la convergencia de las reflexiones moralizantes del estoicismo y del pensamiento cristiano. En consonancia con este lugar común, también se ha repetido, una y otra vez, que los griegos de la época arcaica y clásica no habrían manifestado reparos ante la circunstancia que un

\footnotetext{
* Abogado. Profesor de Derecho del Trabajo y Seguridad Social. Facultad de Derecho, Universidad de Chile.

${ }^{1}$ Así en SCHÜnemann, B. "Libertad de voluntad y culpabilidad en Derecho penal", en: Temas actuales y permanentes del Derecho penal después del milenio. Madrid: Tecnos, 2002 p. 24.
} 
individuo fuera castigado por un hecho personal involuntario o, inclusive, por el crimen de terceros. Una voz tan autorizada, como la de Otto, afirma que, entre los griegos, no existe el libre albedrío ni la libertad, tal como nosotros los conocemos: "Quien yerra, no lo hace por mala voluntad. Esta no existe para el griego, quien ni siquiera tiene una palabra para lo que nosotros llamamos 'voluntad' "2.

Lo cierto es que la literatura griega ofrece innumerables ejemplos de individuos que habrían sido castigados por faltas involuntarias o por crímenes de sus ancestros. En la tragedia ática, el parricidio e incesto involuntarios de Edipo aparecen como la causa de terribles desgracias que caerán, primeramente, sobre la ciudad de Tebas, azotada por la peste; luego sobre el propio gobernante, Edipo y, finalmente, a sobre toda su progenie. Sus dos hijos varones, Eteocles y Polinices, morirán en fratricida lucha ${ }^{3}$ y su hija Antígona terminará ajusticiada por dar sepultura al cadáver de este último. Podríamos incluso remontar la genealogía de Edipo y situar la causa de estas desgracias, no en sus propias acciones sino, en las de su padre, Layo. Es la hipótesis de Cantarella, según la cual "en el origen de los males que se cernieron sobre Tebas se encuentra un suceso que tuvo lugar en

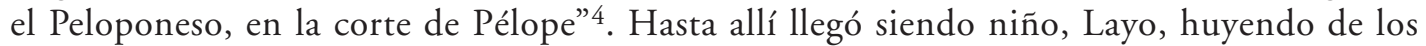
usurpadores del trono paterno y, ya adulto, devolvió, de mala manera la hospitalidad recibida. En efecto, cuenta Apolodoro que "cuando enseñaba a Crisipo, hijo de Pélope, a conducir un carro, se enamoró del joven y lo raptó" 5 . Según una de las tradiciones relativas a esta historia, "Crisipo, que no pudo sobrellevar la vergüenza, se suicidó, y, entonces, Pélope lanzó una maldición sobre Layo: si tuviese un hijo, moriría a manos de este" 6 . Edipo, por ende, no sería más que una rueda de engranaje en la máquina incesante de castigos y expiaciones puesta en marcha por la violación cometida por su padre Layo.

Análogo mecanismo pone en movimiento Tántalo, el padre de Pélope, “que con los dioses compartía la dignidad de una mesa común”, cuando intenta poner a prueba la inteligencia de los sempiternos, invitándoles a comer un plato con la carne de su propio hijo. Tántalo será castigado con cruel suplicio por esta burla impía. Pero, como señala Cantarella, "esto es solo el primer acto de una saga de lo más truculenta" 8 , pues la siniestra acción de Tántalo, será imitada en el plazo de dos generaciones por su nieto Atreo, quien, para vengar un adulterio, mata, descuartiza y cuece a los tres hijos de su hermano Tiestes y se los sirve en un espantoso banquete. Luego que Tiestes consume el último bocado, su hermano le revela la macabra procedencia de la carne ofrecida en el festín. Tiestes huye horrorizado. Este crimen de Atreo le traerá muerte y perdición tanto a él como a sus descendientes, los átridas. Tiestes engendrará, cometiendo violación e incesto, a Egisto, quien a su vez matará a Atreo y, con la ayuda de Clitemnestra, al hijo de aquel y marido

\footnotetext{
${ }^{2}$ OтTO, W. F., Teofanía. El espíritu de la antigua religión griega. Madrid: Sexto Piso, 2007, p. 57.

${ }^{3}$ Vid. Esquilo: Siete contra Tebas.

${ }^{4}$ Cantarella, E. El dios del amor. Una introducción a los mitos y leyendas de la Antigüedad. Barcelona: Editorial Paidós, 2009, p. 63.

5 Apolodoro: Biblioteca, III, 5, 5. Ateneo, quien también se refiere al rapto de Crisipo, señala que algunos atribuyen a Layo el inicio de "estas prácticas amorosas" (la pederastia) en la Grecia continental (Deipnosofistas, XIII, 602). Vid., también Sergent, B. La homosexualidad en la mitología griega. Barcelona: Editorial Alta Fulla, 1986 pp. 75 y ss.

${ }^{6}$ Cantarella, E., op. cit. (n. 4), p. 63.

${ }^{7}$ Eurípides, Orestes, 10.
} 
de esta, Agamenón, apenas vuelto de Troya. Orestes, hijo de Agamenón y Clitemnestra, vengará la muerte del padre liquidando sin piedad a sus asesinos.

Nos resulta difícil aceptar que actos inicuos de un individuo, como los de Layo o Tántalo, traigan el castigo sobre toda una ciudad o sobre toda una estirpe. El hecho es que, muy tempranamente, los griegos trasladaron el concepto de Dike del mundo social humano al mundo en general ${ }^{9}$. Anaximandro hablará de una justicia cósmica que preside la generación y disolución de los seres. Célebre es su sentencia: "de donde las cosas tienen su origen, hacia allí deben sucumbir, según la necesidad; pues tienen que expiar y ser juzgadas por su injusticia, de acuerdo al orden del tiempo" ${ }^{10}$. Heráclito, con su igualmente famoso fragmento 94 ("el Sol no rebasará sus medidas; que, si las rebasare, las Erinias, servidoras de la Justicia, sabrían encontrarlo"11) se inscribe, precisamente, en esta tendencia, característica de los presocráticos, a derivar de las experiencias del mundo humano los conceptos para la interpretación del mundo natural ${ }^{12}$. Según una interpretación del fragmento:

“a la hipótesis de una transgresión, es decir, de una obstinación del sol en querer permanecer encendido más allá de la medida prefijada, Heráclito opone la ineluctabilidad de su muerte nocturna: ineluctabilidad que presenta bajo la figura de las Erinnias ministras de Dike, que reprimirían la tentativa de infracción castigándolo de muerte" 13 .

Lo transgredido por el sol es la ley natural que regula su ciclo diario, pero esa ley ata también al hombre. "En este sentido, la insuperabilidad de los límites fijados según Heráclito a la vida del sol de cada día particular, corresponde al idéntico destino que domina la vida de cada individuo humano particular..."14. Como advierte De Romilly, "la idea del orden del universo era [...] un viejo argumento para convencer del respeto a las leyes [humanas]" 15 . Pero no se trata solo de una analogía entre fenómenos paralelos que, por decirlo así, marchen por cuerda separada, ya que para los griegos la conducta humana transgresora ofende también a la Dike cósmica. Ellos pensaban que actos inicuos de un mortal podrían trastrocar el orden justo del universo y producir consecuencias cósmicas. Como advierte Hesíodo, la primera víctima de la injusticia es el propio malhechor: "un hombre, maquinando males para otros, los maquina para sí mismo, y una mala decisión es malísima para quien la toma”. Pero, además, la injusticia perjudica a toda la ciudad, puesto que "el ojo de Zeus, que todo lo ve y todo lo comprende [...] ve esto y no le pasa

\footnotetext{
${ }^{8}$ Cantarella, E., op. cit. (n. 4), p. 51.

9 JAEGER, W. Alabanza de la Ley. Los origenes de la filosofía del derecho y los griegos. Madrid: Instituto de Estudios Políticos, 1953. p. 34 .

10 Según la traducción de Nietzsche, citada por Heidegger, M. "La sentencia de Anaximandro", en Caminos de bosque. Madrid: Alianza editorial, 1998. p. 239.

11 GarCía-BaCCA, J.D. Los presocráticos. -2a ed.-, México: Fondo de Cultura Económica, 2007, p. 247.

12 Mondolfo, R. Heráclito. Textos y problemas de su interpretación. 13a edición-. México: Siglo XXI editores, 2007, p. 244.

13 Zeller, citado por Mondolfo, R. op. cit. (n. 12), p. 248.

${ }^{14}$ Ibid.

15 De Romilly, J. La ley en la Grecia clásica. Buenos Aires: Editorial Biblos, 2004, p. 114.
} 
inadvertida qué clase de justicia la ciudad encierra dentro". El poeta advierte que "muchas veces toda una ciudad participa de la suerte de un hombre malo que es culpable y maquina locuras". Y, así, se afirma que para el pensamiento de los antiguos, una culpa que no es imputable subjetivamente, pero que objetivamente existe con toda gravedad, es una abominación para los dioses y los hombres y puede infectar al país entero ${ }^{16}$.

Por otra parte, Aristóteles señalará que la desgracia inmerecida es un elemento esencial de la tragedia, puesto que el efecto propio de este género es, junto al temor, la compasión y, según el estagirita, "la compasión se funda en lo inmerecido de la desdicha"17. Según Von Fritz, la necesidad de culpa individual como fundamento del castigo, ajena a los grandes áticos, procede de una transformación introducida en la tragedia (y que marca el fin de la misma) por una tendencia estoico-moralizante, atribuyendo un papel relevante en esta transformación a Séneca ${ }^{18}$. Incluso se ha afirmado -teniendo presente al Edipo sofócleo- que "el pesimismo de este héroe surge del hecho de que en él lo trágico no procede ni de una $h$ "bris 'soberbia', ni de una hamartía 'error', sino simplemente de la circunstancia involuntaria de existir"19.

Ahora bien, la tajante afirmación de que el mundo antiguo ignora el concepto de culpa personal, pudiera obedecer a una visión demasiado simplista, que convendría matizar. Y nuevamente la literatura nos proporciona preciosa evidencia.

Consultemos el primer monumento de la literatura griega, la Ilíada de Homero. Agamenón amenaza a Aquiles con arrebatarle su botín de guerra, a "Briseida, de bellas mejillas". Entonces "la aflicción invadió al Pélida, y su corazón dentro del velludo pecho vacilaba entre dos decisiones: o desenvainar la aguda espada que pendía a lo largo del muslo y hacer levantarse a los demás y despojar él al Atrida, o apaciguar su cólera y contener su furor" ${ }^{20}$. La diosa Hera envía prestamente a Atenea a apaciguar la furia del héroe. Esta lo conmina a cesar la disputa y no desenvainar la espada porque, le adelanta, llegará el día en que el propio Agamenón "te ofrecerá el triple de tantos espléndidos regalos a causa de este ultraje: tú domínate, y haznos caso" ${ }^{21}$. A la tesis de Otto, según la cual "[f]rente a esta presencia inmediata del dios, nuestra noción de libertad humana pierde todo sentido", cabe oponer la aguda observación de SNELL, quien destaca que "Atenea no hace valer su poder, ni siquiera dicta su severa orden, sino que da a Aquiles un motivo de reflexión..."22.

Por su parte, los griegos de tiempos de Pericles parecían conocer la distinción jurídica entre un crimen voluntario y uno involuntario, a efectos de su castigo. Plutarco nos refiere que "con ocasión de que uno de los atletas en los juegos había herido y muerto

\footnotetext{
${ }^{16}$ LESKY, A. La tragedia griega. Barcelona: Acantilado, 2001, p. 69.

17 Poética, XIII.

${ }^{18}$ VON FRITZ, K. "Tragische Schuld und poetische Gerechtigkeit in der griechischen Tragödie", en: Antike und modern Tragödie. Neun Abhandlungen. Berlin: 1962.

19 BAUZÁ, H.F. El mito del héroe. Morfología y semántica de la figura heroica. Buenos Aires: Fondo de Cultura Económica, 1998. p. 119.

${ }^{20}$ Homero, Ilíada, I, 188-192.

${ }^{21}$ Homero, op. cit. (n. 20), I, 213-214.

22 Snell, B. El descubrimiento del espiritu. Estudios sobre la génesis del pensamiento europeo en los griegos. Barcelona: Acantilado, 2007, p. 279.
} 
involuntariamente con un dardo a Epitimo de Farsalia", Pericles y su amigo, el sofista Protágoras, debatieron todo un día "si sería el dardo, o el que le tiró, o los jueces del concurso, a quien conforme a recta razón se diese la culpa de aquel accidente" 23 .

Heródoto, por su parte, nos cuenta la historia de Adrasto, que fue desterrado por haber matado, sin querer, a su hermano. Creso, rey de los lidios, lo purifica del crimen y lo acoge en su palacio. Con ocasión de una batida contra un jabalí que asolaba los campos, Adrasto, lanza su venablo contra el animal, pero yerra el tiro y le da al hijo de Creso, causándole la muerte. Adrasto comparece ante el rey y le pide que lo inmole junto al cadáver del príncipe:

"pero Creso, al oír estas palabras, y a pesar de hallarse sumido en una desgracia personal tan grande, se compadeció de Adrasto y le dijo: 'Ya he recibido de ti, extranjero, una cumplida satisfacción, pues tú mismo te condenas a muerte. Pero no eres tú el responsable de este infortunio -salvo en la medida que fuiste su involuntario autor material-, sino probablemente un dios, el mismo que ya hace tiempo me predijo lo que iba a suceder"' 24 .

Retomando el ejemplo de los átridas, en la tragedia esquílea la culpa ancestral es, por decirlo así, actualizada en cada generación por el linaje de Atreo. Así, Agamenón cumple con la voluntad de Zeus al destruir Troya, pero cometiendo crímenes terribles (la destrucción de los templos y altares y el sacrificio de su propia hija, Ifigenia).

Por su parte, Orestes cumple la voluntad de Apolo al matar a Clitemnestra, la adúltera asesina de su marido Agamenón, pero al vengar la sangre paterna el héroe se convierte en matricida. El "caso Orestes" es complejo. Bajo el viejo sistema feudal, los clanes estaban atados por vínculos de sangre. Orestes, por ser el consanguíneo más próximo de Agamenón, estaba obligado a vengar a su padre. Pero al cumplir con este deber cometió, a su vez, un crimen abominable. Las Furias reclaman la venganza de la sangre materna vertida por Orestes. Estas representan a los dioses primigenios y defienden un concepto primitivo de justicia, forjado en los oscuros tiempos del matriarcado. Los dioses olímpicos simpatizan con Orestes. Podrían, sin más, desdeñar a las Erinias y darle la razón a aquel. Sin embargo, Esquilo, por boca de Atenea, nos advierte sobre las consecuencias de semejante arbitrariedad:

"Empero unos derechos tienen estas/ que no resulta fácil conculcar, / y si no alcanzan fallo victorioso/ en este pleito, invadirá la tierra/ el veneno de su resentimiento,/ peste insufrible". Atenea decide, entonces, someter el asunto a un juicio justo: “...escogeré/ jueces atados por gran juramento/ y luego en un augusto tribunal/ lo tornaré, que dure para siempre./ Buscadme los testigos y las pruebas, / juramentado auxilio del derecho./ Yo voy recoger la flor y nata/ de mi ciudad, y volveré al instante/ para que justamente el pleito fallen/ sin transgredir en nada el juramento/ con espíritu inicuo y alevoso".

\footnotetext{
23 Vidas Paralelas, Pericles, XXXVI.
}

${ }^{24}$ Historia, I, 45. 
Tendrían que pasar muchos siglos para que la dogmática penal concibiera las "causales de justificación", que eliminan la ilicitud de un acto que de no concurrir alguna de ellas sería delito. No obstante, un germen de estas aparece en el llamado que hace Orestes a Febo para que testifique a su favor: "Explícame, oh Apolo, si la vida/ le quité justamente. Porque el hecho/ tal como sucedió, yo no lo niego". Apolo recurre a un tecnicismo machista "del hijo no es la madre engendradora, / es nodriza tan solo de la siembra/ que en ella se sembró./ Quien la fecunda/ ese es engendrador...” Por tanto el deber de vengar la muerte paterna se sobrepone sobre el castigo del matricidio. Los jurados están divididos en iguales partes a favor de Orestes y de las Erinias. El empate lo dirime Atenea con argumentos no menos machistas: “...Soy, sin reserva, / del bando de mi padre. De este modo, / no prefiero el destino de una hembra/ que muerte dio a su esposo, de una casa/ dueño y señor. Orestes gana el pleito/ aunque haya empate". Esquilo confronta, de una parte, una concepción patriarcal de la sociedad frente a una matriarcal, más primitiva, y, por otra, nos muestra, en lenguaje mítico, la sustitución del viejo principio de retribución del "ojo por ojo" por la nueva legalidad de la Polis, capaz de una sutileza que consigue superar también la culpa objetiva.

$\mathrm{Y}$ es que el héroe de la tragedia esquílea debe tomar siempre una decisión grave que desencadenará su desgracia. Ciertamente, con pocas opciones: "pero ello no significa, ni mucho menos, que Esquilo pretenda anular la libertad humana y la responsabilidad del héroe: lo que sí hay, en esta decisión, es una cierta ambigüedad, como si el poeta no deseara insistir demasiado en el juego de culpa/castigo, que, sin embargo, planea en toda la acción trágica" 25 .

El héroe trágico puede obrar de otra manera. Antígona pudo obedecer el decreto de Creón dejando insepulto el cadáver de su hermano y, sin embargo, prefiere cometer un crimen contra la ciudad, pero cumplir las leyes divinas. Ella será castigada. No obstante, Adrasto y Orestes serán absueltos, el primero, como homicida involuntario y, el segundo, por haber ejecutado el matricidio en el cumplimiento de un deber.

NIETZSCHE observó, con extrema agudeza, que: "Casi cada tiempo y cada grado de cultura han intentado alguna vez, con profundo malhumor, liberarse de los griegos, porque, en presencia de estos, todo lo realizado por ellos, en apariencia completamente original y sinceramente admirado, parecía perder de súbito color y vida y reducirse, arrugado, a una copia mal hecha, más aún una caricatura" 26 .

\section{REFERENCIAS BIBLIOGRÁFICAS}

1.- Autores Antiguos

APOLODORO: Biblioteca.

ARISTÓTELES: Poética.

ATENEO: Deipnosofistas.

\footnotetext{
${ }^{25}$ Alsina, J. "La Orestía” (estudio preliminar), en: Esquilo, Tragedias completas. Barcelona: Editorial Altaya, 1994, p. 215

${ }^{26}$ Nietzsche, F., El nacimiento de la tragedia, -1 a ed. 1973, 12a Reini. Madrid: Alianza, 1994., pp.125-126.
} 
ESQUILO: Orestía; Siete contra Tebas.

EURÍPIDES: Orestes.

HERODOTO: Historia.

HESIODO: Trabajos y dias.

HOMERO: Ilíada.

PLUTARCO: Vidas Paralelas.

SÓFOCLES: Edipo Rey; Antígona.

2.- Autores modernos:

AlsinA, J. "La Orestía" (estudio preliminar), en: Esquilo, Tragedias completas. Barcelona, Editorial Altaya, 1994.

BAUZA, H.F., El mito del héroe. Morfología y semántica de la figura heroica. Buenos Aires: Fondo de Cultura Económica, 1998.

Cantarella, E., El dios del amor. Una introducción a los mitos y leyendas de la Antigüedad. Barcelona, Editorial Paidós, 2009.

De Romilly, J., La ley en la Grecia clásica. Buenos Aires, Editorial Biblos, 2004.

García-BACCA, J.D., Los presocráticos -2a ed-. México: Fondo de Cultura Económica, 2007.

Heidegger, M., "La sentencia de Anaximandro", en: Caminos de bosque. Madrid: Alianza editorial, 1998.

JaEger, W. Alabanza de la Ley. Los orígenes de la filosofía del derecho y los griegos. Madrid, Instituto de Estudios Políticos, 1953.

LESKY, A. La tragedia griega. Barcelona, Acantilado, 2001.

Mondolfo, R. Heráclito. Textos y problemas de su interpretación -13a edición-. México, Siglo XXI editores, 2007.

Nietzsche, F. El nacimiento de la tragedia. -1a ed. 1973, 12a Reini. 1994-. Madrid, Alianza, 1994.

Отто, W. F., Teofanía. El espiritu de la antigua religión griega. Madrid, Sexto Piso, 2007.

SCHÜNEmAnN, B. "Libertad de voluntad y culpabilidad en Derecho penal", en: Temas actuales y permanentes del Derecho penal después del milenio. Madrid, Tecnos, 2002.

SERGENT, B. La homosexualidad en la mitología griega. Barcelona, Editorial Alta Fulla, 1986.

SNELL, B. El descubrimiento del espíritu. Estudios sobre la génesis del pensamiento europeo en los griegos. Barcelona, Acantilado, 2007.

VON FRITZ, K. “Tragische Schuld und poetische Gerechtigkeit in der griechischen Tragödie”, en: Antike und modern Tragödie, Neun Abhandlungen. Berlín, 1962. 
